Brit. F. industr. Med., 1968, 25, 209.

\title{
Determination of Lead in Blood by Atomic Absorption Spectrophotometry ${ }^{1}$
}

\author{
STIG SELANDER and KIM CRAMÉR \\ with the technical assistance of BIRGITTA BÖRJESSON and GUNILLA MANDORF
}

From Medical Service I and the Department of Hygiene, University of Göteborg, Göteborg, Sweden

Lead in blood was determined by atomic absorption spectrophotometry, using a wet ashing procedure and a procedure in which the proteins were precipitated with trichloroacetic acid. In both methods the lead was extracted into isobutylmethylketone before measurement, using ammonium pyrrolidine dithiocarbamate as chelator. The simpler precipitation procedure was shown to give results identical with those obtained with the ashing technique. In addition, blood specimens were examined by the precipitation method and by spectral analysis, which method includes wet ashing of the samples, with good agreement. All analyses were done on blood samples from 'normal' persons or from lead-exposed workers, and no additions of inorganic lead were made. The relatively simple protein precipitation technique gave accurate results and is suitable for the large-scale control of lead-exposed workers.

The principal methods used for the determination of lead in blood have been dithizone extraction, polarography, and spectral analysis. They are all well known and give accurate results in skilful hands, but the analytical procedures are usually time-consuming and complex. Comparisons of results obtained in different laboratories with the same or different methods have also shown a great divergence (Byers, 1959; Hoschek, 1963).

Atomic absorption spectrophotometry (AAS) provides a new, sensitive, and specific method. Different procedures for the treatment of blood samples before the estimation of lead in the spectrophotometer have been published. Berman (I964) precipitated the blood proteins with trichloroacetic acid (TCA) and then extracted the lead in the supernatant with ammonium pyrrolidine dithiocarbamate (APDC) into isobutylmethylketone. In Io cases there was a good agreement with the results obtained with a colorimetric dithizone extraction method. Pierce and Cholak (1966) used a modification of this method and also a method involving dry ashing of the samples, but without subsequent extraction of the lead into an organic solvent. The results were in reasonable agreement with those

\footnotetext{
${ }^{1}$ Aided by grants No. B-66-374 and No. B-67-6rP-2094-0I from the Swedish Medical Research Council and by a grant from Försäkringsföretaget Folksam, Stockholm, Sweden.

Received for publication February 19, 1968.
}

obtained with spectrographic and dithizone methods. However, only samples with added lead were analysed. Slavin and his colleagues (Slavin, Sprague, Rieders, and Cordova, I964) suggested a method using digestion of blood with nitric acid as the only treatment of the samples before the atomic absorption analysis. Only recoveries of added lead were estimated. The agreement with chemical analysis was said to be satisfactory, but no data were given. Sprague and Slavin (1966) used the method of Berman (1964) but without the extraction technique, and only samples with added lead of known amounts were analysed.

Our experience with the analysis of lead in urine has made us suspicious of the reliability of methods which are too simple and of methods based only on results from an analysis of samples with added inorganic lead (Selander and Cramér, 1968). For example, our results with blood digested with $\mathrm{HNO}_{3}$ were discouraging. The method of Berman (1964) is attractively simple and it also includes extraction of the lead into an organic solvent. However, it has been questioned whether some lead is lost in the protein precipitate (Slavin and Sprague, 1964). We have therefore compared a modification of Berman's method with a slight modification of the method we use for analysis of lead in urine, which includes wet ashing of the samples (Selander and Cramér, 1968). Samples with added lead were not used, but as a control of 
the AAS results a comparison was made with those obtained with a spectral analytical method (Danielsson, 1952).

\section{Materials and Methods}

Instrumentation, Instrumental Settings, and Reagents These were, with two exceptions, the same as those in our previous paper on the determination of lead in urine (Selander and Cramér, I968): (I) the main part of this work was done with a shielded hollow cathode lamp, which needs a current of $30 \mathrm{~mA}$; and (2) TCA solution, 5\% (Merck, Darmstadt) was used for protein precipitation. Fresh solutions should be prepared daily.

Analytical Procedures The blood samples were collected in heparinized ro-ml. glass test-tubes containing I mg. sodium heparin ${ }^{1}$. When the samples were stored or were transported a fairly long way, this was not sufficient to prevent clotting, and the analyses were unreliable. In such circumstances a few drops of heparin solution (40 mg. sodium heparin $/ \mathrm{ml}$.) were added to each blood sample.

Wet Ashing The blood sample was digested by a mixture of concentrated nitric acid and concentrated sulphuric acid $(5: 2 \mathrm{v} / \mathrm{v}$.). The oxidation was completed by hydrogen peroxide. After adjusting the $p \mathrm{H}$ to about 3.0 with concentrated ammonia the lead was extracted by APDC into isobutylmethylketone before analysis.

This was essentially the same procedure as that used for the determination of lead in urine (Selander and Cramér, 1968), but with a sample volume of only $5 \mathrm{ml}$., and with ro ml. of digestion reagent. During the ashing there was a strong tendency to frothing, which could be avoided by digesting in two steps with $5 \mathrm{ml}$. digestion reagent used in each. For the final oxidation about $10 \mathrm{ml}$. of hydrogen peroxide were needed to reduce the colour to a light yellow. The colour was not as pale as that of ashed urine samples. After the ashing the extraction procedure was exactly the same as in the determination of lead in urine.

Standard solutions were treated like blood samples except that only $5 \mathrm{ml}$. of the digestion reagent were used. The $p H s$ of both were then about the same after ashing

${ }^{1}$ AB Vitrum, Stockholm, Sweden. and the same amounts of ammonia were needed to adjust the $\mathrm{pH}$.

TCA Precipitation Five $\mathrm{ml}$. of whole blood and Io $\mathrm{ml}$. of a $5 \%$ TCA solution were mixed in a centrifuge tube, allowed to stand for one hour with occasional stirring, and spun for ro minutes at 3,000 r.p.m. The supernatant was decanted into a separating funnel. A further ro $\mathrm{ml}$. of $5 \%$ TCA solution were added to the precipitate in the centrifuge tube and stirred vigorously for a few minutes. The tube was spun again for ro minutes, and the supernatant was decanted into the separating funnel. The $p \mathrm{H}$ was adjusted to about $3 \cdot 0$ with concentrated ammonia. The lead was extracted with APDC into isobutylmethylketone as before. After ashing, the extraction efficiency is constant over the $p H$ range 2.5 to 4.5 (Selander and Cramér, 1968). This was confirmed for TCA precipitation of blood samples. The standard solutions were treated in the same way to provide calibration.

Light Scattering Effects, Sensitivity, and Detection Limits For the wet ashing method these matters have been discussed for analyses of urine (Selander and Cramér, 1968). The conclusions applied also to analyses of blood, but it should be noted that the sample volume was reduced to one-half, i.e., to $5 \mathrm{ml}$., for blood. The TCA precipitation method, followed by the same extraction technique as for the wet ashing method, gave the same results also: light scattering at $2203.5 \AA$ gave an absorbance of about 0.009 for blood samples and for standard solutions. A lead concentration in blood of about $0.05 \mu \mathrm{g} . / \mathrm{ml}$. gave an absorption of $\mathrm{I} \%$, as a measure of the analytical sensitivity. With standard instrumental settings the detection limit was about $0.04 \mu \mathrm{g} . / \mathrm{ml}$., but using scale expansion $\times 3$ and a noise suppression setting of 4 , it could be extended to $0.0 \mathrm{I}$ $0.02 \mu \mathrm{g} . / \mathrm{ml}$. (Fig. I).

\section{Results and Discussion}

Comparison of the Wet Ashing and TCA Methods Twenty-five blood specimens were analysed by both methods. The results are given in Table I. Eight specimens were from patients without known lead exposure, 12 from patients with occupational lead exposure, and 5 from patients with lead poisoning during treatment with sodium
Fig. I. Absorption traces for $0.02 \mu \mathrm{g} . / \mathrm{ml}$. lead and for a blank solution, obtained at scale expansion $\times 3$ and noise suppression setting 4 .

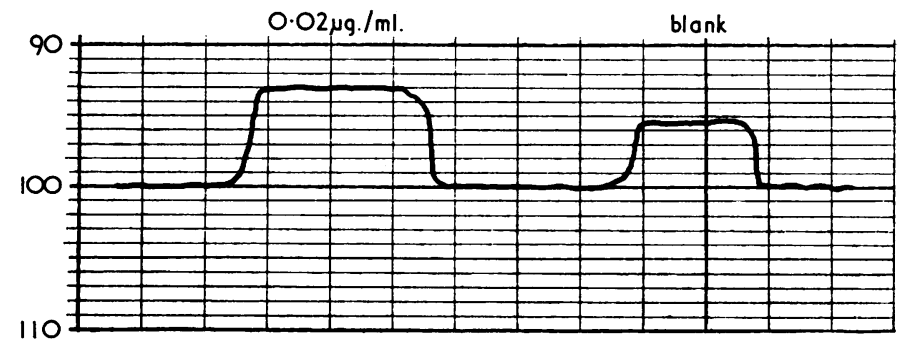


TABLE I

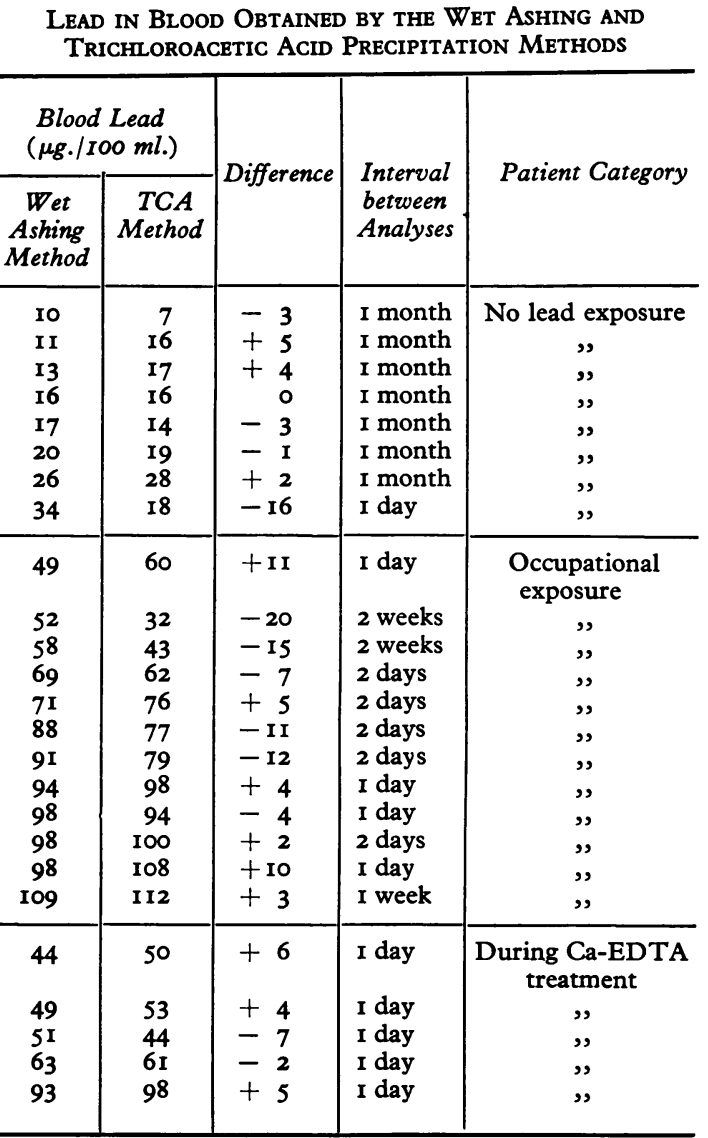

calciumedetate. The interval between the analyses by the two methods varied from one day to four weeks. From Table I it can be seen that the difference between the results by the two methods was not influenced by the sodium calciumedetate therapy nor by the length of the interval between the analyses.

The relationship between the two methods can be described by a regression line (Fig. 2) with the equation:

$$
\mathrm{TCA}=\mathbf{I} \cdot 006 \mathrm{WA}-\mathbf{I} \cdot 953
$$

where TCA represents the values obtained after TCA precipitation and WA the values obtained after wet ashing of the blood samples. The correlation was good $(r=0.970)$, and the regression line is not different from the line of identity (dotted line, Fig. 2). Thus it is evident that the two methods gave comparable results and that the fear of a loss of lead in the TCA precipitate (Slavin and Sprague, 1964) was not justified. The TCA method is to be pre-

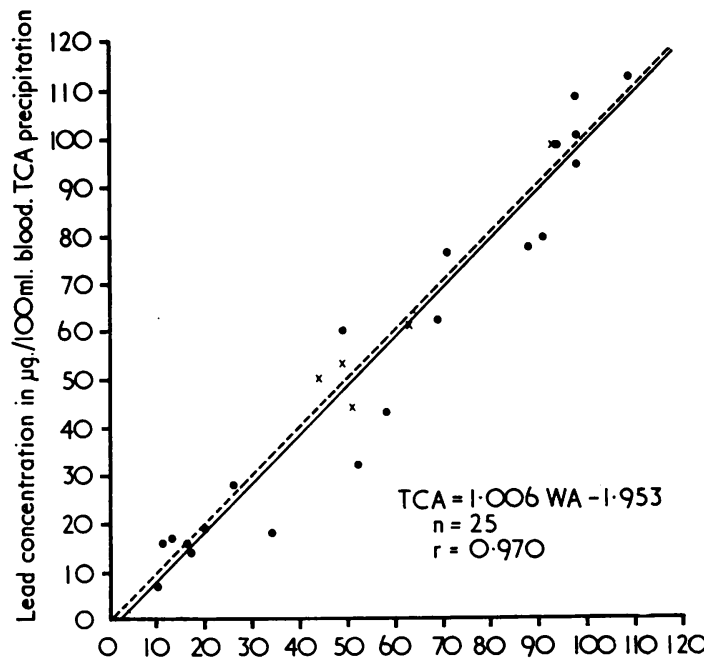

Lead concentration in $\mu g . / 100 \mathrm{ml}$. blood. Wet osting

Fig. 2. Comparison of wet ashing (WA) and trichloroacetic acid (TCA) precipitation methods for AAS determination of lead in blood. The dotted line is the line of identity. $X=$ samples from patients treated with sodium calciumedetate.

ferred as it is less time-consuming and less elaborate. Two laboratory assistants can easily perform 25 duplicate determinations in one day. We now use the method routinely for the control of lead-exposed workers. The error of a single determination was I 95 $\mu \mathrm{g}$./ $100 \mathrm{ml}$., calculated from duplicate determinations on 25 blood samples (every tenth analysis during the last five months). The lead concentration of the samples varied between 12 and $90 \mu \mathrm{g} . / 100 \mathrm{ml}$.

Comparison of AAS (TCA Precipitation) and Spectral Analytical Methods This comparison was made on 47 blood samples and the results of the analyses by the two methods are given in Table II. The spectral analytical analyses were performed at the laboratory of the Boliden Melting Works, Skelleftehamn, Sweden. The samples had to be transported about $I, 000 \mathrm{~km}$. by ordinary mail, and then frozen and stored for some time before analysis.

Twenty-six samples were from lead-exposed workers at the Boliden Melting Works. Of the 2 I samples from Göteborg, 13 were from workers exposed to lead and 8 were from parking guards.

The interval between the analyses by the two methods was about two weeks.

The relationship between the methods can be described by a regression line (Fig. 3):

$$
\mathrm{AAS}=\mathrm{I} \cdot 003 \mathrm{SA}+4 \cdot 375 \text {, }
$$


TABLE II

Lead in Blood Obtained by the Spectral analytical AND AAS (TCA PRecipitation) Methods

\begin{tabular}{|c|c|c|c|}
\hline \multicolumn{2}{|c|}{ Blood Lead ( $\mu \mathrm{g} . / \mathrm{I} 00 \mathrm{ml})}$. & \multirow{2}{*}{ Difference } & \multirow{2}{*}{ Patient Category } \\
\hline $\begin{array}{l}\text { Spectral } \\
\text { Analysis }\end{array}$ & $\begin{array}{c}A A S \\
\text { (TCA precipitation) }\end{array}$ & & \\
\hline $\begin{array}{l}13 \\
14 \\
15 \\
15 \\
16 \\
17 \\
18 \\
20\end{array}$ & $\begin{array}{l}12 \\
17 \\
19 \\
19 \\
16 \\
18 \\
19 \\
19\end{array}$ & $\begin{array}{l}-1 \\
+\quad 3 \\
+\quad 4 \\
+\quad 4 \\
\quad 0 \\
+\quad 1 \\
+\quad 1 \\
-\quad 1\end{array}$ & $\begin{array}{c}\text { Parking guard } \\
\text { ", } \\
\text { ", } \\
\text { ", } \\
\text { ", } \\
\text {," }\end{array}$ \\
\hline $\begin{array}{l}19 \\
20 \\
21 \\
21 \\
32 \\
32 \\
32 \\
33 \\
33 \\
35 \\
35 \\
37 \\
38 \\
39 \\
41 \\
42 \\
43 \\
43 \\
43 \\
45 \\
46 \\
47 \\
48 \\
49 \\
52 \\
52 \\
52 \\
53 \\
54 \\
56 \\
57 \\
58 \\
60 \\
61 \\
64 \\
70 \\
73 \\
74 \\
82\end{array}$ & $\begin{array}{l}29 \\
23 \\
28 \\
30 \\
37 \\
42 \\
42 \\
27 \\
44 \\
30 \\
43 \\
53 \\
43 \\
38 \\
40 \\
48 \\
48 \\
50 \\
51 \\
53 \\
47 \\
52 \\
62 \\
55 \\
54 \\
60 \\
64 \\
62 \\
57 \\
53 \\
56 \\
55 \\
79 \\
61 \\
72 \\
69 \\
78 \\
73 \\
84\end{array}$ & $\begin{array}{l}+10 \\
+\quad 3 \\
+7 \\
+9 \\
+5 \\
+10 \\
+10 \\
-6 \\
+11 \\
-5 \\
+8 \\
+16 \\
+5 \\
+1 \\
-1 \\
+6 \\
+5 \\
+7 \\
+8 \\
+8 \\
+\quad 1 \\
+5 \\
+14 \\
+6 \\
+2 \\
+8 \\
+12 \\
+9 \\
+3 \\
+3 \\
-1 \\
-\quad 3 \\
+19 \\
+8 \\
+8 \\
+\quad 1 \\
+5 \\
+1 \\
+\quad 2\end{array}$ & 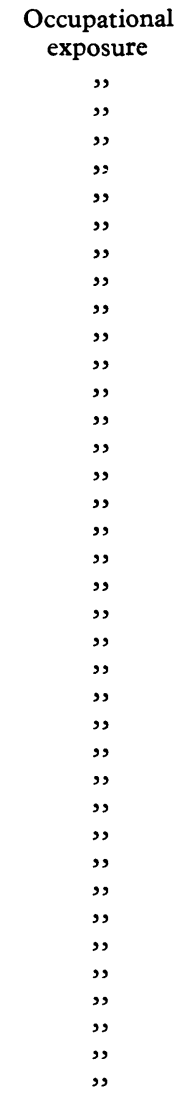 \\
\hline
\end{tabular}

where SA represents the values obtained with the spectral analytical method. The correlation is good $(\mathbf{r}=0.957)$. It appears that the AAS method gave somewhat higher values $(4.4 \mu \mathrm{g} . / 100 \mathrm{ml}$ ) $(0.044$ $\mu \mathrm{g} . / \mathrm{ml}$.) than the spectral analytical method, but the regression line is not statistically different from

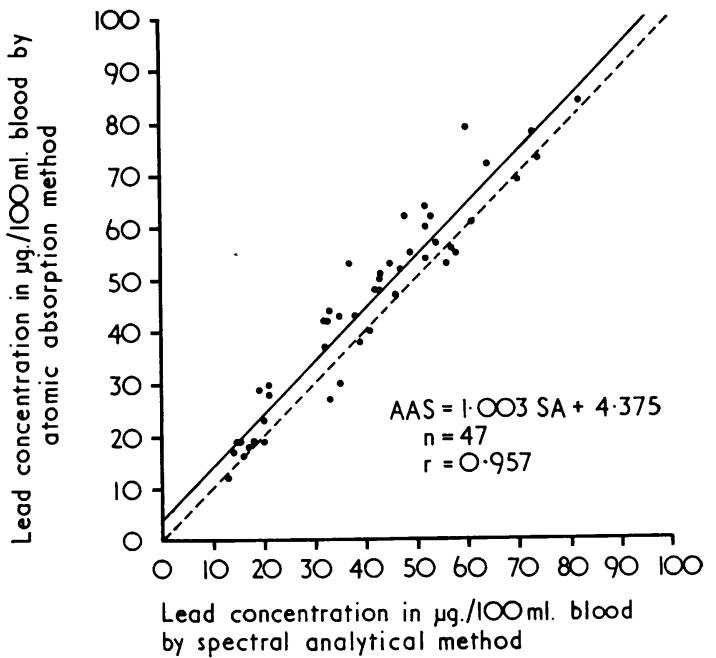

FIG. 3. Comparison of spectral analytical (SA) and AAS (TCA precipitation) methods for determination of lead in blood. The dotted line is the line of identity.

the line of identity. Thus, there was good agreement between the results.

\section{Conclusion}

Spectral analysis is considered to be the most exact of all existing methods for the determination of lead. The present comparison demonstrated that the much simpler and less expensive equipment for atomic absorption spectrophotometry can give almost identical results. The two AAS methods gave identical results, so that determination of lead in blood does not require ashing of the samples, in contrast to the determination of lead in urine (Selander and Cramér, 1968). Therefore the more simple TCA precipitation method is to be preferred and is well suited for large-scale application in the control of workers exposed to lead.

Thanks are due to Dr. Holmqvist for performing the spectral analytical analyses.

\section{REFERENCES}

Berman, E. (1964). The determination of lead in blood and urine by atomic absorption spectrophotometry. Atomic Absorption Newsletter, 3, I I I-I I4. No. 9.

Byers, D. H. (1959). An evaluation of blood lead analyses. Industr. Med. Surg., 28, II7-I2I.

Danielsson, A. (I952). Eine Methode zur Bestimmung von Blei im Blut mittels Spektralanalyse. Schr. Ges. Dtsch. Metallhütten- und Bergleute, No. 3, pp. 97-107.

Hoschek, R. (1963). Parallelbestimmungen des Bleispiegels in verschiedenen Instituten. Int. Arch. Gewerbepath. Gewerbehyg., 20, 195-216. 
Pierce, J. O., and Cholak, J. (1966). Lead, chromium and molybdenum by atomic absorption. Arch. environm Hlth, 13, 208-212.

Selander, S., and Cramér, K. (1968). Determination of lead in urine by atomic absorption spectrophotometry. Brit. F. industr. Med., 25, I39-143.

Slavin, W., and Sprague, S. (1964). The determination of trace metals in blood and urine by atomic absorption spectrophotometry. Atomic Absorption Newsletter, 3, I-6. No. I7.

—, Sprague, S., Rieders, F., and Cordova, V. (1964). The determination of certain toxicological trace metals by atomic absorption spectrophotometry. Ibid., 3, 7-Io. No. 17.

Sprague, S., and Slavin, W. (1966). A simple method for the determination of lead in blood. Ibid., 5, 9-10. 